usually due to poor dies, can easily be missed if the direction of the X-ray beam lies far from the plane of the crack. The necessity of close collaboration between radiologist and foundry manager was emphasized, and the procedure followed by $\mathrm{Mr}$. Bailey himself was described. The breaking-up of castings in order to confirm and supplement radiographic inspection is essential, especially for the detection of microshrinkage; this is helped by heattreating the castings before breaking, the oxidation resulting making the microshrinkage more readily visible.

A lengthy discussion followed these papers and was contributed to by many speakers. Practical details, both difficulties which have been encountered and hints to overcome them, were mentioned, among the latter being the use of rubber cassettes which can be evacuated to hold intensifying screens in close contact with the film, the advantage of these being their flexibility, enabling them to be adjusted to close contact with irregularly shaped bodies; and the use of mercury for blocking off holes in an other- wise uniform plate. The most important point raised during the discussion, however, was the need for standardization of the acceptable limit for given types of fault. It was generally agreed that standards for welds would not be too difficult to formulate, particularly since welds are usually in material of uniform section and regular shape, but it would be much less easy to arrive at similar standards for castings. The responsibility for the determination of standards was discussed and there was agreement that the final decision should rest with the designer of a component, the function of the radiologist being to interpret the radiographs to the designer.

It was decided that the Radiology Group of the Institute of Physics is not in a position to undertake the preparation of radiographic standards, but Dr. L. Mullins, the secretary of the Group, pointed out that standardization is very necessary in other fields, and hopes, for example, that the Group will be able to put forward suggestions which will result in a reduction of the many different types and sizes of camera used in X-ray diffraction work.

\title{
TECHNICAL ABILITY AND THE WAR EFFORT
}

\begin{abstract}
A PRIME necessity in a war-time economy is for the maximum and most efficient use of all the country's resources. Particularly necessary in this War is the full use of technical-man-power. After two years of war, when it is implied by Government spokesmen that we still lack sufficient material to contemplate an offensive against the enemy, it is disquieting to learn that there still exists a widespread misuse of technical man-power.

At a national conference for members in engineering and aircraft industries, held at Birmingham on September 7 under the auspices of the Association of Scientific Workers, delegates stated that many industrial scientists and technicians are still working on peace-time problems. Others with insufficient work to do are being kept together as teams and find the Essential Work Order used to prevent release from their present firms and the transfer of their ability elsewhere. Delegates made it clear that this situation has arisen from the concern of some industrial firms with the problems of post-war competition. Speakers criticized the absence of any proper pooling of information. They spoke of production being held up while technicians completed designs or solved problems already dealt with by a parallel organization, and of the withholding of full technical information from designers of apparatus.

There was criticism of the scientific ability of some persons at present in charge of technical staff. A delegate from the aircraft industry spoke of technical leadership being in the hands of former racing drivers.

Many speakers felt that the combination of inefficient management, the concern of firms for private interests, the scheduling of overtime as a pretence of activity when there is insufficient work to do and similar experiences have given rise to a general apathy regarding production and that it is necessary for this to be broken down by close co-operation between marıgement and employees.
\end{abstract}

The remainder of the conference dealt with working conditions in these industries. Cases were put forward of qualified men receiving less remuneration than workmen under their supervision. Strong exception was taken to the system whereby university graduates rated as student apprentices are put on to ordinary production work at nominal salaries. Speakers clearly felt that little improvement in the status of scientific workers would be effected unless the Association of Scientific Workers could establish a minimum salary scale for all grades of scientific and technical staff.

The Conference therefore passed the following resolutions :

(1) All technical staffs not fully engaged on the war effort or engaged on development in preparation for post-war competition should be transferred to other departments.

(2) Real pooling of technical information and facilities should take place between firms producing similar articles, and between Government depart. ments and firms producing for them.

(3) All scientific and technical work should be under the direction only of persons with adequate technical experience and qualifications.

(4) There should be genuine co-operation between managers and workpeople to secure greater enthusiasm for the war effort.

(5) An attitude of vigilance should be adopted regarding the working of the Essential Work Order, so that it shall not be allowed

(a) to hinder the war effort by permitting managements to retain staff when their transfer would be in the national interest;

(b) to serve as an instrument of victimization of active trade unionists.

To carry this programme into effect the Conferenee proposed several points of action for the consideration of nembers of the Association, full details of which can be obtained from the Association of Scientific Workers, 30 Bedford Row, London, W.C.1. 